\title{
Editorial
}

\section{Measuring the World of Books: Scales, Proportions, Formats, and Classifications}

\begin{abstract}
A book is just an object. As any other object, when you look at it carefully it shows itself as a complex aggregate of elements. Books are industrial objects that must be assembled; esthetic works that ought to be designed; commodities that have to be sold; conveyors of information that need to be storaged; banks of knowledge that could be distributed or censored; repositories of copyrighted material that are required to be protected; pieces in a library that shall be classified and cataloged; items in a bookshelf that should fit in their place. To fulfill all these functions books have to be measured, scaled, formatted, standardized, and classified.

The articles in this special issue of InfoDesign explore the origin and workings of the conventions that we use to measure and classify books. Topics range from the measurement of paper and typography, to historical episodes about the arrangement books in the early modern Americas, to the current systems of book classification in libraries and the copious amount of numbers printed within books employed for their identification and control.

Books get under the observance of measurers and classifiers due to two parallel processes: industrialization and rationalization. When Gutenberg invented the mechanical movable type he not only opened the floodgates to the massive production of book, but also kickstarted industrialization as such. Industrialization —combined with long distance trade- required a single set of measures to enhance its effectiveness. Industrial processes and mechanization replaced traditional forms of book production. Modern printing techniques produced thousands of identical books, adjusted to dimensions that have to be regulated by precise measurements. Books - which were previously made manually - started to be massively produced; and standardized measures began to be more widely used in the world of books. The novel methods of production brought the need for standardization; both supplies (like paper) and machine parts (like type) were required to conform to predefined patterns and sizes to fit into modern and rapidly evolving printing machinery. The articles by German Fraustro Nadal and Oriol Moret Viñals show the intricate ways in which some of these standardization processes took place.

On the other hand, the new world of knowledge that printed books carried with them created the demand for methods and systems to
\end{abstract}

\begin{tabular}{l|l} 
InfodesIgn & Revista Brasileira de Design da Informação/Brazilian Journal of Information Design \\
& São Paulo | v. 11 | n. 2 [2014] ISSN 1808-5377
\end{tabular} 
order and classify that enormous wealth of information. Through the centuries, countless techniques to organize books in libraries and repositories were developed, in a quest that eventually became projects to rank and arrange human knowledge itself. Many rational systems of book classification - by rational we mean systematic, rigorous, methodical, coherent, and predictable systems- appeared, with the hope to make information easy to store, trace, and retrieve. The articles by Manuel Suárez Rivera, Víctor Cid Carmona and Claudia Escobar Vallarta, and Héctor Vera show the workings of some of those systems, past and present.

The studies included in this special issue of Infodesign point to a specific design theme addressed from various scientific and academic backgrounds, in which the book — as a cultural artifact - and its mensuration became a central topic of interest and reflection.

We hope that this volume will be of interest to readers and that the articles will allow us to move into new grounds in the critical studies linking information design and book studies.

\section{Marina Garone Gravier and Héctor Vera}

Editors 